\title{
Conjugalidades múltiplas nas travestilidades e transexualidades: uma revisão a partir da abordagem sistêmica e da psicologia social
}

\author{
Transvestites and transsexual multiple conjugalities: a systemic and social psychology \\ review \\ Eduardo Lomando', Henrique Caetano Nardi
}

\footnotetext{
'Mestre em Psicologia Social pela Pontifícia Universidade Católica do Rio Grande do Sul.(PUC-RS) - Porto Alegre (RS), Brasil. Professor de Psicologia na Faculdade de Desenvolvimento do Rio Grande do Sul (FADERGS) - Porto. Alegre (RS), Brasil.

eduardolomando@yahoo.com

${ }^{2}$ Doutor em Sociologia pela Universidade Federal do Rio Grande do Sul (UFRGS) - Porto Alegre (RS), Brasil. Professor do Departamento e do Programa de Pós-Graduação em Psicologia Social e Institucional da Universidade Federal do Rio Grande do Sul (UFRGS) - Porto Alegre (RS), Brasil.

hcnardi@gmail.com
}

RESUMO: O objetivo deste artigo é realizar uma revisão da literatura brasileira sobre as conjugalidades nas experiências de travestis e de homens e mulheres transexuais. Os resultados dos oito trabalhos encontrados indicam um número variado de nomenclaturas dessas parcerias, com uma aparente fusão emocional conjugal, que funciona como mantenedora das identidades de gênero das/os participantes. Entretanto, encontram-se respostas criativas, que permitem a quebra do efeito halo entre identidade de gênero e desejo sexual, conduzindo à autonomia identitária e ao prazer.

PALAVRAS-CHAVE: Pessoas transgênero; Identidade de gênero; Transexualidade; Travesti; Estado conjugal; Sexualidade.

ABSTRACT: The goal of this article was to perform a Brazilian literature review in relation to the conjugalities in the experiences of transvestites and transsexual men and women. The results of the eight papers found show a variety of forms to denominate these partnerships, with an apparent conjugal emotional fusion that works as a maintainer the participants' gender identities. However, there are creative responses that allow an interruption in the halo effect between gender identity and sexual desire and lead to identity autonomy and to pleasure.

KEYWORDS: Transgender people; Gender identity; Transsexuality; Transvestite; Conjugal status; Relationship; Sexuality. 


\section{Introdução}

Qual é a diferença entre travestis e transexuais? É frequente essa pergunta quando se aborda o tema, e uma das primeiras respostas dadas traz, sem necessariamente dar-se conta, o discurso médico-psiquiátrico: travestis se sentem homem e mulher, ao mesmo tempo, e não querem 'cortar' seu pênis. Já as transexuais se pensam mulheres, por isso querem operar. Entretanto, no decorrer do processo de compreensão dessas vivências, é possível observar que essa resposta é carente e que existem muitos outros saberes capazes de responder à pergunta, de formas complementares, paralelas e antagônicas. Inclusive, respostas que colocam as transexualidades e as travestilidades, em algumas questôes, nos mesmos territórios. A conjugalidade é uma delas.

Percebe-se que para compreender as conjugalidades transexuais não é possível deixar de lado as experiências de parceria das travestis. Não é o objetivo deste artigo aprofundar o debate sobre as diferenças e semelhanças das vivências transexuais e travestis, pois, além de já existirem trabalhos que se dedicaram a essa temática (PELÚCIO, 2006; GALLI, 2008; KULICK, 2008; BARBOSA, 2010; LEITE JUNIOR, 2011), a questão se situa muito mais em uma autodefinição identitária do que em limites precisos que a ciência ou a lei possam delimitar. O que divide o mundo das/os transexuais e travestis pode estar nos campos discursivos médico, psicanalítico, social e experiencial. Mas algo que os/as une está exatamente na experiência identitária conflitante com as normas de gênero (BENTO, 2008), embora, nesse caso, a partir de um agente concreto, que metaforiza essas dinâmicas simbólicas: o/a cônjuge (cisgênero ou não). Don Kulick (2008), em um dos primeiros e mais importantes trabalhos etnográficos com travestis da cidade de Salvador/BA, na década de 1990, afirma que a maioria dos estudos sobre prostituição enfatiza a relação com a clientela, como se essa fosse a parte mais importante no universo das profissionais do sexo. Entretanto, afirma que

[...] eu logo descobri que os namorados [...] são uma referência central e constante na vida delas. Os namorados consomem uma enorme quantidade de tempo, das conversas, dos pensamentos - sem falar do dinheiro - das travestis. Elas orientam-se constantemente em função de seus namorados, ex-namorados e futuros namorados [...] Sem compreender o papel dos namorados, fica impossivel compreender qualquer outra dimensão da vida das travestis. (KULICK, 2008, P. 114).

A importância de compreender essas experiências está em buscar explorar se a experiência de conflito com a norma produz efeitos na conjugalidade, nos trabalhos que se dedicaram a pesquisar esse tema. Assim, o objetivo foi revisar a literatura em português, no contexto brasileiro, sobre as experiências conjugais de homens e mulheres transexuais e travestis. A escolha da revisão por conveniência se deve ao fato de já termos realizado uma revisão sistemática sobre o tema e de não termos encontrado, utilizando aquela técnica específica, diversos artigos e livros nacionais importantes nesse campo. Além disso, o objetivo deste trabalho não é generalizar a análise sobre os aspectos e as dinâmicas dessas relaçóes, mas, sim, buscar agrupar e analisar as direçóes escolhidas pela literatura para a compreensão do tema. Com isso, pretende-se aprimorar o conhecimento dos profissionais das ciências da saúde e humanas e usá-lo como um gatilho para reflexáo a respeito das narrativas de casais de travestis e de homens e mulheres transexuais sobre suas próprias experiências.

Para tanto, foram revisados três livros (KULICK, 2008; PELÚCIO, 2009; NERY, 2011), um capítulo de livro (CARDOZO, 2007), duas dissertaçóes de mestrado (GALLI, 2013; ORNAT, 2008) e dois artigos (PELÚCIO, 2006; SEFFNER; MÜLLER, 2012), totalizando oito trabalhos. A tabela 01 resume as características de cada trabalho. Depois da leitura e da análise de cada texto, foram destacadas quatro temáticas referentes às relaçóes conjugais de travestis e de homens e mulheres transexuais, que emergiram dos textos. São elas: (1) nomenclaturas dadas aos parceiros; (2) escolha conjugal e transgeracionalidade; (3) negociação sexual e autoafirmação; e, por último, (4) flexibilidade e criatividade. 


\section{Análise inicial}

Antes de analisar a questão a partir das temáticas propriamente ditas, é fundamental fazer alguns apontamentos.
Primeiramente, apesar da escolha da revisão por conveniência, nota-se uma quantidade superior de trabalhos sobre travestis profissionais do sexo, em detrimento de mulheres transexuais e, menos ainda, de homens

Quadro 1. Características dos trabalhos analisados

\begin{tabular}{|c|c|c|c|c|}
\hline AUTOR (A) & ANO & DELINEAMENTO & PARTICIPANTES & ÁREA \\
\hline Don Kulick & $\begin{array}{l}2008 / \\
1998^{1}\end{array}$ & $\begin{array}{l}\text { Qualitativo, etnografia, 08-12 } \\
\text { meses, convivência diária } \\
\text { com travestis. }\end{array}$ & $\begin{array}{c}35 \text { travestis, profissionais do } \\
\text { sexo (PS) de Salvador/BA. }\end{array}$ & $\begin{array}{l}\text { Ciências Sociais } \\
\text { (Antropologia) }\end{array}$ \\
\hline Larissa Pelúcio & 2006 & $\begin{array}{l}\text { Qualitativo, entrevistas com } \\
\text { três casais. }\end{array}$ & $\begin{array}{c}\text { Dois casais de travestis PS, com } \\
\text { homens cis e um casal de duas } \\
\text { travestis PS do Estado de SP. }\end{array}$ & $\begin{array}{l}\text { Ciências Sociais } \\
\text { (Antropologia) }\end{array}$ \\
\hline $\begin{array}{l}\text { Fernanda } \\
\text { Cardozo }\end{array}$ & 2008 & $\begin{array}{l}\text { Qualitativo, entrevistas } \\
\text { semiestruturadas. }\end{array}$ & 6 travestis PS de Florianópolis/RS. & Ciências Sociais \\
\hline Márcio Ornat & 2008 & Qualitativo, grupo focal. & $\begin{array}{c}11 \text { travestis PS de Ponta Grossa/ } \\
\text { PR. }\end{array}$ & $\begin{array}{l}\text { Geografia } \\
\text { (Gestão do } \\
\text { território) }\end{array}$ \\
\hline Larissa Pelúcio & 2009 & $\begin{array}{l}\text { Qualitativo, etnografia, } \\
\text { observação participante. }\end{array}$ & $\begin{array}{c}\text { Travestis PS, parceiros de travestis } \\
\text { e T-lovers do Estado de SP. }\end{array}$ & Ciências Sociais \\
\hline João W. Nery & 2011 & Autobiografia & $\begin{array}{l}\text { Autobiografia como homem } \\
\text { trans, incluindo seus } 5 \\
\text { relacionamentos. }\end{array}$ & - \\
\hline $\begin{array}{l}\text { Fernando } \\
\text { Seffner \& } \\
\text { Magnor Müller }\end{array}$ & 2012 & $\begin{array}{l}\text { Qualitativo, entrevistas e } \\
\text { observações. } \\
\text { Participantes por } 2 \text { anos. }\end{array}$ & $\begin{array}{c}\text { Três casais de travestis PS e } \\
\text { homens cisgêneros da região } \\
\text { metropolitana de Porto Alegre/ } \\
\text { RS. }\end{array}$ & Educação \\
\hline Rafael Galli & 2013 & $\begin{array}{l}\text { Qualitativo, entrevistas } \\
\text { semiestruturadas. }\end{array}$ & $\begin{array}{l}15 \text { pessoas de Ribeirão Preto/ } \\
\text { SP que se autodefinem como: } \\
\text { transexual (6), travesti (2), } \\
\text { transgênero (1), transex (2) e } \\
\text { mulher (1). Duas participantes } \\
\text { não se definiram nas categorias } \\
\text { existentes. }\end{array}$ & Psicologia \\
\hline
\end{tabular}

1 A publicação em inglês é de 1998, porém sua tradução para o português ocorreu somente 10 anos após.

FONTE: Formatação própria. 
transexuais. $\mathrm{O}$ único trabalho sobre homens trans no qual a conjugalidade é analisada é a autobiografia de João Nery. Compreendemos que isso se deve ao fato de que a denominação 'travesti' seja uma construção social de longa data, ancorada na cultura brasileira. Por outro lado, a denominação 'transexual' é relativamente recente no contexto nacional. Em segundo lugar, a grande maioria dos trabalhos (07 de 08) foi produzida depois do ano de 2006, constituindo a conjugalidade uma temática extremamente nova nas pesquisas sobre travestis e transexuais. Por último, percebe-se que todos os trabalhos são qualitativos, não havendo trabalhos de caráter quantitativo, com amostras representativas dessa população.

\section{Nomeando os parceiros}

O subtítulo do texto de Larissa Pelúcio (2009) "Maridos, Bofes, Mariconas e Vício" resume as quatro formas por meio das quais as travestis se referem aos seus companheiros. Quando nomeiam parceiros e não parceiros/ as, a escrita no masculino é proposital, pois verifica-se que essas variaçóes de nomenclatura não aconteceram nos textos relacionados à experiência de homens transexuais ou mesmo de travestis que se relacionam com mulheres cisgêneras. E isso tem uma razão muito peculiar.

Larissa Pelúcio (2009) foi informada pela travesti Danil que "Travesti não tem namorado, tem marido" (p.77), pois a relação que elas estabelecem com homens que não são seus clientes quase sempre inclui a rápida coabitação. O termo 'marido' aparece como proposta de nomeação em oposição ao termo 'namorado', pois conferiria maior estabilidade, uma vez que, no campo da prostituição, ter um marido é sinal de status (KULICK, 2008; SEFFNER; MÜLLER, 2012). Porém, percebese que a valência de um relacionamento como status não é privilégio do mundo da prostituição. As relações conjugais já foram, e continuam sendo, um território que vai além da relação de amor e afeto. Há valores atribuídos socialmente, a partir do século XVIII, que contemplam dinheiro, status, filiação, alianças entre famílias, entre outros aspectos. (ARAÚJO, 2002).
O termo 'vício' é usado para um homem que é cliente, mas que, pelo prazer proporcionado à travesti, pode fazê-la não cobrar pelo programa, e, assim, perder dinheiro (KULICK, 2008). Já os termos 'maricona', 'viado' ou 'gay' são empregados quando o marido ou cliente deseja fazer sexo oral nela ou quando deseja ser penetrado por ela. Por outro lado, os termos 'bofe', 'ocó', 'homem', 'homem de verdade' e 'macho' denotam um homem com características associadas ao estereótipo masculino, tais como: musculoso, tatuado, de fala curta e grossa, ativo sexualmente, 'hétero', viril, agressivo, possessivo, 'bem dotado', alto e jovem (PELÚCIO, 2006; CARDOZO, 2008; KULICK, 2008; PELÚCIO, 2009; SEFFNER; MÜLLER, 2012, GALLI, 2013). João Nery (2011), um dos primeiros homens transexuais da cena pública brasileira, descreve em seu livro que era muito atraído pela beleza, sensibilidade, leveza, sensualidade, charme, vaidade, suavidade e feminilidade de suas parceiras, fazendo referência às características típicas do estereótipo feminino.

Já o termo 'T-lovers' aparece na literatura como adotado pelos parceiros e clientes das travestis. $\mathrm{O}$ ' $\mathrm{T}$ ' estaria no local de Travesti ou Transex, enquanto 'lovers' significa amantes. Assim, esses homens se afirmam como amantes, adoradores e apreciadores das 'T-gatas', como chamam as travestis. Todavia, esse grupo tem normas claras para as condutas sexuais e sociais, pois não querem ser associados à homossexualidade (PELÚCIO, 2009).

\section{Escolha do/a parceiro/a e transgeraciona- lidade: estereótipos e autoafirmação}

Para a Abordagem Sistêmica ${ }^{1}$, a escolha de uma (ou mais) parceria conjugal é um momento fundamental para se compreender a relação, pois é a partir dela que muitas dinâmicas do relacionamento se estabelecerão (ANTON, 2009). Ao contrário do que existe no pensamento popular, esses momentos iniciais de encontros entre pessoas não são mero acaso. As escolhas são movidas por aspectos transgeracionais, ou seja, por valores, crenças, exigências, mitos, segredos, expectativas, entre outros, que são passados através das geraçôes familiares. 
Essas características transgeracionais começam a ser demonstradas e negociadas na relação desde o primeiro encontro. Porém, é mais fácil que os parceiros percebam os aspectos superficiais (como beleza, simpatia, status, escolaridade etc.) do que os aspectos transgeracionais de suas escolhas (FERES-CARNEIRO, 1997; RIOS, 2005; WAGNER 2005). Apesar de alguns aspectos dessas escolhas conjugais aparecerem nas descriçôes e análises presentes nos trabalhos revisados, o que chama mais atenção é a forte motivação das travestis, das mulheres e dos homens transexuais para a escolha de parceiros/as representantes dos estereótipos de gênero.

A escolha de um 'homem de verdade' ou uma 'mulher de verdade, feminina' não é aleatória. Todos os sujeitos, de todos os trabalhos, são pessoas apresentadas como marcadas por duas questôes: uma referência identitária de gênero, outorgada no nascimento (menino ou menina), que se materializa, por exemplo, em um nome de registro. Segundo, uma experiência de construção social de sua própria identidade (travesti, trans etc.), que, quando negociada com a inicial/registro, é vivenciada com rigidez e os/as impossibilita o acesso a diversos direitos. A vida dos/as participantes é marcada pela constante luta social autoafirmatória de suas identidades como travestis, homens/mulheres transexuais ou, até mesmo, como homens ou mulheres. E essa luta, frequentemente, começa de acordo com a forma que os/as autores/as das pesquisas apresentam os sujeitos

\footnotetext{
${ }^{1}$ Resumidamente, a Abordagem Sistêmica é um conjunto de pressupostos teórico-práticos, criados a partir da década de 1950, nos EUA e na Itália, por diversos autores/as, como Bateson, Bowen, Haley, Minuchin, Satir, Palazzolli, Boscolo, entre outros/ as, influenciados por paradigmas como a Cibernética, Teoria Geral dos Sistemas, Construcionismo Social, Construtivismo e, mais recentemente, pelas Teorias Eco-Sistêmicas (NICHOLS; SCHWARTZ, 2007). Atualmente, compreende as relações humanas a partir da intersubjetividade. Ou seja, entende que as singularidades dos sujeitos são produtos e produtores das relações que se tem com os diversos subsistemas com os quais interagimos (sociedade, família, trabalho, amigos, cultura etc.), em uma organização complexa, interativa e mais suscetível a probabilidades de resultados do que certezas determinantes (VASCONCELLOS, 2002)
}

desses trabalhos em seu núcleo familiar e na rede social mais próxima. É, geralmente, na relação com pai, mãe, padrasto, madrasta, irmãos/âs, tios/as, sobrinhos/as, avôs/ós, vizinhos/as etc. que a batalha 'ontológica' entre menino/homem e menina/mulher tem seu palco inicial. Cardozo (2008) relata que as travestis entrevistadas não se importavam tanto com o fato de seus familiares as tratarem pelo masculino, desde que as nomeaçóes fossem "usadas com respeito" (p.242), da mesma forma que Nery (2011) conta que, mesmo argumentando, era forçado a usar vestidos e laços de cabelo pela mãe.

$\mathrm{Na}$ literatura sistêmica, o conceito de transgeracionalidade é, frequentemente, visto como intrafamiliar. Entretanto, esses valores, crenças e mitos familiares com relação a sexo, gênero e sexualidade não fazem parte de um aspecto que se restringe somente ao núcleo da família, mas que circula de forma independente da complexidade sociocultural (WAGNER, 2005). No tocante ao gênero e à sexualidade, suas raízes fazem parte de duas lógicas macrossociais interligadas, denominadas "heterossexualidade compulsória" (RICH, 2010) e "heteronormatividade" (BUTLER, 2012). De forma geral, enquanto a primeira lógica faz com que as pessoas assumam, automaticamente (compulsão), e avaliem o mundo social como sendo heterossexual, a não ser que comprovado de outra forma, a segunda mantém uma regra social (norma) binária (homem ou mulher), que afirma uma continuidade e uma congruência entre sexo/gênero/sexualidade, definindo como anormais (fora da norma) todas as narrativas, expressões e práticas que divirjam das linearidades pênis/masculino/atração-por-mulheres e vagina/feminina/atração-por-homens.

Assim, escolher um/a parceiro/a que é mandatário de uma polaridade de gênero pode ativar, através do uso dessas lógicas, uma representaçáo social polarizada e oposta. Imaginemos um exemplo: uma pessoa qualquer observa um casal passeando na rua, sendo um deles uma representação estereotípica de um homem (como caracterizada anteriormente). A lógica da heterossexualidade compulsória poderá fazer com que esse observador pense que ao lado desse 'homem' somente poderia estar uma 'mulher', não outro homem. Assim como essa estratégia pode funcionar em direção ao exterior, ela funciona, principalmente, como um vetor constituinte da 
singularidade desses casais, tomando os relatos tal como apresentados pelos/as autores/as, pois a escolha de um/a parceiro/a estereotipado/a é um componente que os/as ajudaria na afirmação de suas próprias identidades. Entretanto, essas performances também acabam por agir como reforços da heteronormatividade: "Um dos requisitos fundamentais do marido [...] é, pois, a garantia do desempenho ativo, reforçando nelas sua feminilidade» (SEFFNER; MÜLLER, 2012, p.290). Nas relaçôes das travestis, "está claro quem é a 'mulher' e quem é o 'homem', uma vez que dentro do sistema simbólico próprio das travestis" (PELÚCIO, 2006, p.542) as relações entre pessoas que nasceram com o mesmo 'sexo' só podem ser compreendidas se os polos masculino e feminino estiverem presentes. Nery (2011, p.77-8) conta: “Quando era solicitado a me colocar numa posição de 'receber', sentia-me ameaçado, como se confundido com uma fêmea”. Da mesma forma que algumas mulheres transexuais e transgêneras entrevistadas por Galli $(2013$, p.157) "se esforçam ao máximo e têm o discurso de gênero como um elemento importante de seu roteiro sexual".

Dessa forma, quando eles/as naturalizam o sexo, mantêm-se ligados/as a essa matriz heteronormatizadora e, "Informadas por uma gramática de conjugalidade heterossexual, as travestis (e os/as transexuais) têm dificuldade em elaborar um outro léxico para as relações conjugais que desenvolvem" (PELÚCIO, 2006, p.532). De forma irônica, mas própria da realidade pesquisada, Kulick (2008) afirma que, quando uma travesti tem uma relação com um 'viado' ou uma 'maricona', isso causa um curto-circuito conceitual no sistema de crenças das travestis, e faz com que elas se sintam como 'lésbicas'. O autor conta que um casal de travestis que namoravam era constantemente agredido verbalmente pelas outras. Não necessariamente pela sua escolha conjugal, mas porque esse aspecto compelia as travestis agressoras a justificar, sem um pedido formal, suas próprias escolhas conjugais. Para refletir sobre essas dinâmicas, tomemos ferramentas da abordagem sistêmica para buscar uma melhor compreensão.

Murray Bowen (1992), um dos primeiros teóricos da abordagem sistêmica a investigar as relaçóes de família e casal, propôs que as relaçóes pessoais de intimidade podem variar de uma fusão relacional a uma diferenciação de self. De forma geral, a fusão emocional acontece quando duas ou mais pessoas compartilham problemas dos quais não conseguem dar conta individualmente, criando exigências externas, muitas vezes não conscientes, para resolvê-los. $\mathrm{Na}$ fusão emocional, há uma constante vigilância e uma ansiedade de separação desse outro. Bowen disserta que, quando cada pessoa cria um espaço singular na relação e consegue, gradativamente, não mais depender emocionalmente do outro, dá um grande passo para diferenciar-se como sujeito. Isso não significa cortar os contatos emocional e social, mas, sim, diferenciar as suas emoçôes e exigências das dos outros, e, a partir disso, reagir a elas.

Assim, por um lado, a necessidade de um/a parceiro/a que corresponda ao estereótipo de gênero pode estar encobrindo a problemática vivida pelas travestis, pelos homens e pelas mulheres trans com as suas próprias identidades de gênero, através do olhar da abordagem sistêmica sobre os relatos apresentados. Buscar uma parceria estereotipada e demandar uma performance rígida de gênero pode demonstrar a entrega dessa tarefa a/ao parceira/o, de salvaguardar a suposta feminilidade ou masculinidade das/os participantes. Não se busca, aqui, afirmar que esse seja um processo específico dos homens e das mulheres trans e das travestis, pois homens e mulheres cis também podem acionar o/a companheiro/a como forma de assegurar uma posição identitária através do gênero e da sexualidade. O que está em questão é que o não reconhecimento social das identidades trans poderia produzir uma tensão maior nesse cotidiano. Isso os/as torna detentores/as de um equilíbrio instável, que gera ansiedade nos homens e nas mulheres transexuais e travestis.

Segundo muitos desses estudos (PELÚCIO, 2006; CARDOZO, 2008; KULICK, 2008; PELÚCIO, 2009; SEFFNER; MÜLLER, 2012, GALLI, 2013), essa ansiedade pode estar ligada ao medo que as/os transexuais e travestis têm de ver seus/suas companheiros/as demonstrando comportamentos que não correspondam ao regramento de gênero, pois isso as/os faria perder suas próprias identidades:

Esse feminino construido e constantemente aperfeiçoado (pelas travestis) atravessa as relaçóes 
conjugais e, certamente, não se faz apenas para agradar aos clientes da prostituição. Ele guarda estreita relação com a masculinidade dos seus maridos, que é algo 'dado', não precisa ser 'aperfeiçoado', apenas 'demonstrado'... (ele) serve para delimitar a relaçấo entre os gêneros. (SEFFNER; MÜLLER, 2012, p. 289).

A relação estreita de gênero das parcerias é vista como algo 'dado' pelos/as participantes, provavelmente, porque tais características foram incluídas na busca dessa/e parceira/o, e, logo, não há aprimoramentos necessários, já que nâo existiria a possiblidade de outra escolha. A questão da fusão emocional está, precisamente, na exigência da constante demonstração desse gênero 'dado'. Não que a demonstração de performances estereotipadas seja um problema em si. Mas, como veremos, essa exigência impede qualquer flexibilidade nas posiçôes de gênero e, usualmente, anuncia o fim do relacionamento. Um dos locais que emerge em todos os trabalhos como território dessa vigilante performatividade é a cama, na hora do sexo.

\section{Na cama de pregos: o leito como territó- rio rígido da (auto)afirmação}

Para as travestis e para mulheres e homens transexuais das pesquisas em análise, que tanto mantinham essa dicotomia de gênero como afirmativa de suas identidades quanto a exigia nas relaçóes conjugais, a cama era sempre a 'prova final' dessa rígida negociação:

A cama é a arena onde alguns individuos de sexo masculino se tornam 'homens' (ao penetrarem um parceiro), e onde alguns outros se tornam 'mulheres' (ao se deixarem penetrar por aqueles homens). Portanto, é na cama que o gếnero realmente se estabelece. Mas é também na cama que o risco de deslizamento do gênero se torna mais acentuado. É ali que se experimenta 'a hora $H$ ' [...] (um parceiro de uma travesti) acreditava que se eu ficar fazendo esse tipo de coisa (sexo anal), eu vou deixar de ser homem, né? [...] Eu preciso me dominar, né. (KULICK, 2008, p. 140)

As participantes de Galli (2013) que se prostituiam definiam aqueles clientes que pediam para ser penetrados por elas como "não homens" (p.158), sublinhando a preocupação de não existirem mais 'homens de verdade' no mundo. Da mesma forma, Ornat (2008) sintetizava as narrativas de muitas de suas entrevistadas na fala de duas delas: "na relação sexual, a travesti deveria ser passiva e o companheiro ativo" (p.69); e "com os namorados a situação muda de contexto. Com eles, ela ‘jamais' fez papel de ativa.” (p.98). João Nery (2011, p.85), narrando sua relação com Mercedes, fala do grande desconforto de ficar nu na frente da parceira, pois, no seu entender, ela o veria como "igualzinho a ela. Enquanto vestido, mantinha certo porte". Conta que aprendeu a manipular a genitália da sua parceira e como isso lhe dava prazer. Porém,

[...] como forma de retribuir a caricia, Mercedes teve a infeliz ideia de tentar tocar na minha genitália. Foi a gota d'agua! Não tive condiçóes mais de aguentar [...] Sabia que a minha impotência não estava na minha sexualidade propriamente dita, mas no meu sexo, enquanto humilhante e vergonhoso. (NERY, 2011, p.89)

As preferências sexuais na cama ou em qualquer outro contexto são plurais e fruto do acoplamento entre as normas sexuais e as experiências de vida. A eroticidade e a busca do prazer e do gozo, segundo os trabalhos aqui analisados, estão mais conectadas com as posiçóes e expressóes de gênero do que com a genitália. A partir da leitura das entrevistas, tal como apresentadas em todos os trabalhos, não fica claro se o pedido de não utilização da genitália faz referência a alguma falta de sensibilidade dessas áreas. Porém, é clara a posição de gênero em que o seu suposto manuseio os/as colocaria. Assim, os/as participantes dessas pesquisas, ao mesmo tempo que relativizam o suposto contínuo entre sexo (genitália)-gênero-orientação sexual, a partir de suas 
identidades trans e travestis, recriam uma suposta essência (KULICK, 2008; PELÚCIO, 2009).

Assumir uma identidade de gênero/sexual discordante da norma não é uma tarefa fácil, principalmente em um país onde a violência e o índice de assassinatos de travestis, gays e lésbicas são muito altos (BRASIL, 2012). Não é surpresa que, dentro desse duro campo de batalha, travestis, homens e mulheres transexuais acabem por seguir as heteronormas, uma vez que em diversos relatos eles/as estão absolutamente sozinhos/as nesses primeiros confrontos. É importante deixar claro que a proposta dessa hipótese explicativa não tem nenhum interesse em culpabilizar as/os participantes dos estudos aqui analisados, individualizar essa questão ou apontar para uma conformação aos arranjos conjugais - como se tratasse de prática absolutamente específica da travestilidade e da transexualidade, sem equivalente na heterossexualidade e na homossexualidade cis, uma vez que toda/os estamos sujeitos à mesma heteronormatividade. Muito pelo contrário. Compreende-se que o sofrimento causado pela transfobia, e vivido pelas/os participantes das pesquisas e por seus parceiros/as, talvez, possa ser um catalizador da reificação das polaridades de gênero como solução.

O objetivo dessa discussão é abrir o feixe de questóes que envolvem a fixidez das possibilidades de expressão identitária e dos arranjos conjugais, que são fruto da violência da heteronorma. Assim, cabe perguntar, seria essa saída normativa a melhor forma de enfrentar o preconceito? Qual é o custo emocional e relacional que essa saída comporta para a qualidade do relacionamento? Como criar autonomia e diferenciação na construção da identidade de gênero face ao preconceito e à violência? As respostas a essas perguntas não são nada fáceis, mas pode-se começar com as palavras de Adrianne Rich (2010, p. 21) sobre o enfrentamento da heterossexualidade compulsória pelas mulheres:

\section{Não há nada em tal critica que nos faça pensar} enquanto vitimas, como se tivéssemos passado por uma lavagem cerebral ou estivéssemos totalmente sem poder. Tanto a coerção como a compulsäo estão entre as condiçóes nas quais as mulheres têm aprendido a reconhecer sua própria força. Resistência é um grande tema no presente ensaio e no próprio estudo da vida das mulheres, se sabemos o que estamos procurando.

E é dessa possível resistência, flexibilidade e criatividade nos encontros relacionais que trata o próximo ponto.

\section{Criatividade, enfrentamento e flexibilida- de relacional}

No início de sua autobiografia, João Nery (2011, p. 74) conta que não desejava uma mulher homossexual, mas uma mulher que fosse heterossexual o bastante a ponto de querer somente homens. Diz ele que "essa necessidade [...] talvez tenha sido a minha maior cruz e burrice na vida. Naquela época, ainda não dimensionava o perigo e a loucura dessa exigência emocional que denominei 'coito perceptivo'". Entretanto, no final de seu livro, ele revê suas experiências e revela:

Solicitava-me nu, com ou sem pau (prótese), de todas as formas. Subia com a lingua pelas minhas costas, me cheirava a nuca e acabava chupando meu pau minúsculo, que crescia em sua boca. Fazia-me gozar [...] Gina me fez conhecer as delicias da passividade. Podia, enfim, sentir uma mulher em cima de mim, me provando, me provocando, me tornando sultáo de todos os sentidos. Tornou-se desimportante o 'coito perceptivo', a certeza de que minha parceira me percebia como um homem para que eu chegasse no orgasmo. Aprendi a não me torturar com minha possivel imagem... (NERY, 2011, p. 266).

A construção da narrativa de vida de João Nery é um potente analisador da recriação possível, que escapa da rigidez na qual a norma busca aprisioná-la. Há dois pontos que surgem nesse relato. Primeiro: quando Nery justifica sua escolha de uma parceira a partir das expressôes de gênero fixas, ele está enfatizando a construção da sua identidade de gênero como homem. Mas, 
quando fala sobre a relação dessa identidade com sua impossibilidade de prazer, limitada pela heteronorma ao coito perceptivo, como conceitua, ele está se referindo aos limites propostos pela norma à exploração erótica de seu corpo. Pode-se afirmar que, no início de sua narrativa, Nery foi vítima do 'efeito halo'.

Descrito por Edward Thorndike (1970), na década de 1920, esse efeito é uma probabilidade de que a avaliação de uma determinada questão interfira no julgamento sobre outros fatores, contaminando o resultado geral e, assim, podendo criar um erro de avaliação. Esse efeito foi mais estudado para comprovar o quanto a primeira avaliação feita de uma pessoa (aparência física, por exemplo) pode influenciar, erroneamente, as demais avaliaçôes sobre a mesma (inteligência, força, competência etc.). Entretanto, pode-se estender seu significado. Quando Nery e os outros/as participantes dos estudos, aqui em análise - e tomando os relatos tal como apresentados pelas/os pesquisadores -, escolhem seus parceiros pelos estereótipos de gênero, estão avaliando que todos os outros efeitos dessa estereotipia aconteceriam. É a suposta correlação, ou efeito halo, entre identidade de gênero e performance erótica. Porém, as questôes e problemáticas das identidades de gênero dos/as participantes das pesquisas em análise estão submetidas à norma que conforma suas existências, o que os/as torna alvos de disputas e de comprovaçóes sociais constantes. Isso pode fazer com que o parceiro/a cisgênero funcione, através da fusão emocional do casal, como segurança e estrutura dessas identidades. Entretanto, são claros nos relatos os altos níveis de conflito conjugal e a baixa capacidade de resolução desses conflitos quando as fusôes ocorrem.

Em razão do efeito halo, Nery e outros/as, ao verificar que a/o parceira/o não terá como cumprir os estereótipos da performance esperada - mesmo porque ela é sempre uma promessa impossível de ser cumprida, se tomarmos a conceituação Butleriana (2012) -, acabam por diminuir a confiança, a autoestima e/ou a segurança em suas identidades de gênero, causando um efeito de desprazer sexual. É o próprio 'coito perceptivo', mas não da percepção do parceiro/a sobre o quanto a travesti ou trans é passiva ou mulher, ou o trans é ativo ou homem; mas, sim, da segurança da percepção que eles/as mesmo têm sobre suas identidades de gênero. É, provavelmente, por esse motivo que Nery declara que esse coito perceptivo foi um grande erro, com grande custo emocional.

Todavia, quando João Nery consegue, finalmente, perceber que está exigindo da parceira algo que, na realidade, é ele que tem de resolver consigo, na sua autodefinição como homem (seja esse homem quem ele quiser), é que finalmente consegue flexibilizar suas práticas eróticas. Um homem passivo que quebra o efeito halo quando toma pra si a autonomia de sua identidade de gênero na relação. João pode, enfim, compreender a percepção que sua parceira (e muitas outras antes dessa) tem dele como 'homem', assim como explorar seu corpo sem perder sua identidade. Essa possiblidade criativa e exploratória foi fruto do enfretamento de uma vida, e ofereceu a João a possibilidade de prazeres sexuais que nunca antes havia explorado.

Além disso, diferentemente das travestis estudadas por Pelúcio (2009) e Kulick (2008), João Nery rearranja léxicos da sexualidade e do gênero para além da heteronorma e do 'coito perceptivo' quando se concebe como um homem transexual que pode ser passivo na cama, e, também, quando renomeia seu órgão genital, batizando-o de 'pau minúsculo'. Um verdadeiro exercício de criatividade singular e conjugal que oportuniza exercícios de saúde emocional e o retira do ciclo da tortura e do sofrimento mental que a heteronorma impóe.

Outras experiências também chamam atenção pela sua pluralidade e pelas construçóes léxicas. Os 'T-lovers' são outro exemplo, pois eles se consideram homens heterossexuais que buscam nas relações sexuais uma ".mulher com algo a mais [...] com um brinquedinho [...] uma vírgula [...] um clitóris avantajado [...] greluda" (PELÚCIO, 2009, p.166). Eles compreendem que o conceito de 'mulher' pode incluir um órgão genital que não é, necessariamente, uma vagina. Muitos relatam, inclusive, gostar de utilizá-lo na relação sexual sem sentir que isso anule a sua identidade de homem. Porém, a ideia de que não são 'homens de verdade', como descrito pelas travestis e mulheres transexuais das pesquisas em análise, pode retirá-los do escopo das opçóes destas como parceiros, assim como das novas possibilidades de viver a sexualidade e o gênero de forma mais criativa e flexível. 
Outras narrativas plurais também são expostas nos trabalhos em análise: a relação amorosa e sexual entre duas travestis com o uso do pênis da relação (PELÚCIO, 2006; KULICK, 2008; ORNAT, 2008 GALLI, 2013) e a relação de travestis e transexuais com mulheres cisgêneras (GALLI, 2013) são exemplos de configuraçôes conjugais que, dependendo do modo como são negociadas, podem desafiar a rigidez normativa de uma suposta linearidade entre sexo/gênero/sexualidade.

\section{Conclusões: desafios à saúde e à educação}

O objetivo deste trabalho foi revisar oito trabalhos que tratam da temática dos relacionamentos conjugais de travestis e de homens e mulheres transexuais. Foram eleitos quatro temas para análise: a) as formas como os/ as participantes nomeavam seus parceiros a partir do tipo de relacionamento que estabeleciam; b) as raízes transgeracionais e as lógicas da heterossexualidade compulsória e da heteronormatividade na escolha desses/as parceiros/as como representantes dos estereótipos de gênero, na busca da autoafirmação identitária, em uma condição fusionada de relacionamento; c) a relação sexual como território dessa vigilância de performatividade; e, por fim, (d) as respostas criativas e flexíveis que esses homens e mulheres transexuais e travestis produziram e que permitem a quebra de uma ligação perigosa entre identidade de gênero e desejo sexual, conduzindo-os/as à autonomia identitária e ao prazer.

Mas qual é a relação entre tais aspectos singulares e conjugais com educação e saúde? Esses homens e mulheres transexuais e travestis ainda enfrentaram caminhos sociais dolorosos para construir suas identidades de gênero em oposição à heteronorma, percurso que começa na família e na rede social mais próxima (escola, igrejas, associaçóes e vizinhança, entre outros espaços de socialização). Mas nem sempre essa batalha é ganha da forma como gostariam, pois o custo é alto. Assim, muitos/as participantes dessas pesquisas trazem e mantêm essa batalha no relacionamento conjugal como busca de uma afirmação identitária. Nesse processo, correm o risco de impor normas de gênero rígidas aos/às parceiros/as, gerar conflitos conjugais, rigidez e fusão emocional, além de aumentarem a chance de dissolução dos relacionamentos. É uma problemática grave, e que, em casos extremos, pode até levar à ideação suicida, como no caso de João Nery (2011, p.78), quando, ao termino de uma relação conjugal, em função da sexualidade: "pela segunda vez, desejei profundamente morrer."

Assim, questiona-se: o que aconteceria se as/os travestis, os homens e as mulheres transexuais, ou qualquer pessoa que divirja das normas de gênero, pudessem ser auxiliados/as a refletir, problematizar e enfrentar as lógicas da heterossexualidade compulsória e da heteronormatividade desde o princípio? Como seria se fossem respeitadas/os nas construções singulares de suas identidades de gênero? Teríamos as mesmas narrativas relatadas pelos pesquisadores e participantes? Será que essas intervenções, partindo de políticas públicas questionadoras e transformadoras, tanto nas escolas quanto nas comunidades e na rede de saúde, poderiam mudar essa insegurança e a necessidade de vigilância dos/as parceiros/as como mantenedores das identidades de gênero?

Ao tomar relatos, tal como apresentados pelos/as pesquisadores/as, corre-se o risco de realçar uma especificidade da conjugalidade transexual e travesti que, de certa forma, poderia reforçar o estigma associado a essas identidades. Assim, torna-se fundamental afirmar que a vigilância das normas de gênero é algo que conforma todas as conjugalidades e marca pactos de submissão rígidos, tanto para a heterossexualidade cis como para a homossexualidade cis. A questão central que se enfatiza é a desconstrução da fusão relacional, seja em que arranjo for. Todavia, e infelizmente, a legitimidade social das trajetórias de vida e das identidades que foram objeto das pesquisas que analisamos é ainda contestada cotidianamente, o que reforça o papel dos profissionais de saúde e educação no rompimento da cadeia violenta da heteronorma. As histórias de mudança e superação relatadas nos estudos aqui analisados dáo pistas de que esse poderia ser o caminho a ser tomado para uma vida mais livre, com menos sofrimento para travestis e homens e mulheres transexuais, assim como para seus/as parceiros/as e a própria relação conjugal. 


\section{Referências}

ANTON, I. C. O casal diante do espelho. Psicoterapia de casal, teoria e técnica. Porto Alegre: Casa do psicólogo, 2009.

ARAUJO, M. F. Amor, casamento e sexualidade: velhas e novas configurações. Psicologia Ciência e Profissão, Brasília, v. 22, n.2, p. 70-77, 2002

BARBOSA, B. C. Nomes e Diferenças: uma etnografia dos usos das categorias travesti e transexual. 2010. Dissertação (Mestrado em Antropologia). - Universidade de São Paulo: São Paulo.

BOWEN, M. Family Therapy in Clinical Practice. Washington: Rowman \& Littlefield, 1992.

BRASIL. Relatório sobre Violência Homofóbica no Brasil: o ano de 2011. Disponível em <http://www.ajuris.org.br/tmp/impr/relatoriohomofobia.pdf>. Acesso em: 03 out. 2012.

BUTLER, J. Problemas de Gênero. 4. ed. Rio de Janeiro: Civilização Brasileira, 2012.

CARDOZO, F. Performatividades de gênero, performatividades de parentesco: notas de um estudo com travestis e suas famílias na cidade de Florianópolis. In GROSSI, M; UZIEL, A. P.; MELLO, L. (org). Conjugalidades, Parentalidades e identidades lésbicas, gays e travestis. Florianópolis: Garamond, 2007.

FÉRES-CARNEIRO, T. A escolha amorosa e interação conjugal na heterossexualidade e na homossexualidade. Psicologia Reflexão e Crítica, Porto Alegre, v. .10, n. 2, 1997, p. 351-386.

GALLI, R. A. Roteiros sexuais de transexuais e travestis e seus modos de envolvimento sexual-afetivo. 2013, Dissertação (Mestrado em Psicologia). - Faculdade de Filosofia, Ciências e Letras de Ribeirão preto. Ribeirão Preto.

KULICK, D. Travesti: prostituição, sexo, gênero e cultura no Brasil. Rio de Janeiro: Editora Fiocruz, 2008.

LEITE JUNIOR, J. "Nossos Corpos Também Mudam": sexo, gênero e a invenção das categorias "travesti" e "transexual" no discurso médico científico. São Paulo: Anablume, 2011.

NERY, J. Viagem Solitária: memórias de um transexual trinta anos depois. São Paulo: Leya, 2011.
NICHOLS, M.; SCHARTZ, R. Terapia familiar: conceitos e métodos. 2. ed. Porto Alegre: Artmed, 2007.

ORNAT, M. J. Território da Prostituição e Instituição do ser Travesti em Ponta Grossa - PR. 2008. Dissertação (Mestrado em Gestão do Território). Universidade Estadual de Ponta Grossa. Rio de Janeiro.

PELÚCIO, L. Três casamentos e algumas reflexões: notas sobre conjugalidade envolvendo travestis que se prostituem. Estudos Feministas, Florianópolis, v.14, n.2, 2006, p. 522-534.

- Abjeção e desejo: uma etnografia travesti sobre o modelo preventivo de aids. São Paulo: Annablume: Fapesp, 2009.

RICH, A. Heterossexualidade compulsória e existência lésbica. Bagoas, Natal, n. 5, 2010, p. 17-44.

RIOS, J. A. Los ciclos vitales de la familia y la pareja. Madrid: Editorial CCS, 2005.

SEFFNER, F.; MÜLLER, M. Quem ama sofre, quem sofre luta, quem luta vence: da conjugalidade entre travestis e seus maridos. Sociedade e Cultura, Goiânia, v. 15, n. 2, 2012, p. 285-295.

THORNDIKE, E. Educational Psychology. Westport, Conn.: Greenwood Press, 1970

VASCONCELLOS, M. J. E. Pensamento Sistêmico. O novo paradigma da ciência. 9.ed. Campinas: Papirus, 2002.

WAGNER, A. Como se perpetua a família?: a transmissão dos modelos familiares. Porto Alegre: EDIPUCRS, 2005.

Recebido para publicação em novembro de 2013

Versão definitiva em dezembro de 2013

Suporte financeiro: não houve

Conflito de interesse: inexistente 